\title{
BUILDING CONSISTENT POLICIES ON SUBSIDIES IN THE FILM INDUSTRY Institutions and Instruments in France and Korea
}

\author{
Patrick Messerlin' \\ Sciences Po Paris \\ patrick.messerlin@gmail.com
}

\begin{abstract}
This paper explores a much-neglected aspect of cultural policies: the role of the institutions in charge and the way they use the instruments at their disposal. It focuses on the film industry which offers the remarkable contrast on how the Korean film industry has outperformed the French one in less than twenty years. This paper provides three conclusions. First, it presents an economic analysis of the French and Korean institutions which shows that building a rich organization with a large degree of freedom for action and granting extensive subsidies is not a sure recipe for the success of the country's film industry. Second, it explains this paradox by the types of subsidies used by the institutions-whether these subsidies target narrowly defined goals (on a film-per-film basis), or have objectives broad enough to benefit potentially all participants in the film industry, such as improving the infrastructure needed for producing films (studios, schools for actors). Last but not least, this paradox is also due to the abundance of subsidies and measures of all types at the disposal of rich institutions, which can easily become a source of costly inconsistencies. This paper provides two illustrations of these conflicts among the instruments provided.
\end{abstract}

\section{Keywords}

consistent film policies; film industry; institutions; principal-agent dilemma; subsidies

\begin{abstract}
About the Author
Patrick Messerlin is Professor Emeritus of economics at Sciences Po Paris, and Chairman of the Steering Committee of the European Centre for International Political Economy (ECIPE) in Brussels. His current research deals with economic and trade relations between Europe and East Asia, with a particular focus on cultural industries.
\end{abstract}


It is often believed that the government should play a key role in developing its nation's film industry. The state is expected to provide the necessary public support that the domestic film industry needs in order to cope with competition from the big-budget blockbusters out of Hollywood. Furthermore, it is also widely accepted that such public support cannot fail: if enough subsidies are granted, national film producers will prosper and achieve success. Nonetheless, there have always been some doubts on these views (as early as, for instance, Kornai), but they have not been backed up by robust information until recently. In his study, Parc has provided solid empirical evidence justifying these doubts. His analysis of the Korean film industry over the very long period of the past few decades shows that the government has had little, if any, role in the industry's success. Rather, this achievement was primarily due to the involvement of business.

Another crucial reason highlighted by Parc to explain Korea's success is that the limited subsidy policy pursued by the government has been based on "indirect" rather than "direct" subsidies. Direct subsidies are those that have a precise targetsupporting the production of a specific film, specific company (TV channels, distributors, or movie theaters), or a specific factor of production (actors speaking a local language or non-permanent crew). In contrast, indirect subsidies-for instance, those granted to develop the infrastructure for the entire film industry, such as studios, cinema schools, or festivals promoting national production-can be beneficial to all participants. Parc's observation has a key consequence: it shifts the focus away from the overall size of subsidies-which has largely dominated the debate on the film subsidies over the last few decades - to the question that is at least as (if not more) crucial from an economic point of view: the nature and structure of the various subsidies granted by a country.

This paper explores further this question by examining an aspect that is often neglected though essential: the "agent" operating the subsidy policy. This approach avoids the frequent misleading assumption that film policies are decided in detail by governments and implemented by them without the intervention of any specialized institutions. This is particularly problematic in the film industry, which is regulated in many countries by institutions specifically designed for (and sometimes by) the industry. For simplicity's sake, they will be referred to as the "institutions" throughout the paper. By the same token, the approach adopted in this paper facilitates a more detailed and pragmatic comparison of the existing practices of these institutions; hence, it provides a better view of the "best" practices.

The paper is organized as follows. The first section explains the reason for comparing France and Korea. In a nutshell, these countries have followed the same broad film policies, but they have witnessed developments of their film industries so different that it raises the question on the true effectiveness of these institutions 
on this evolution. The second section presents the French Centre National du Cinéma et de l'Image Animée (CNC) and the Korean Film Council (KOFIC) and raises the following question: To what extent do these institutions differ in terms of freedom of action, and has this difference had a strong influence on the film policies they have enforced?

The third section shifts the focus from the institutions to the instruments-that is, the subsidies per se. It investigates the economic differences among the wide array of subsidies used by these two institutions. Empirical evidence is provided on the different proportions of direct and indirect subsidies in Korea and France. It also stresses the many problems faced by the rich institutions-such as $\mathrm{CNC}-$ using intensively direct subsidies and how KOFIC's smaller overall subsidy program and stronger focus on indirect subsidies has made it largely immune to these problems.

The last section focuses on an inescapable dilemma: beyond its immediate goal, any film subsidy is doomed to have positive and negative effects on the different segments of the film industry. As a result, the "art" of a good subsidy policy is to balance these costs and benefits by using the most comprehensive analytical framework possible. This key issue is illustrated by analyzing two key instruments: the tax on the seat price which was the cornerstone of both CNC's and KOFIC's subsidy policies, and the tax relief schemes available to foreign filmmakers, which is one of the most recent instruments adopted by many countries.

\section{WHY FOCUS ON INSTITUTIONS AND WHY COMPARE FRANCE AND KOREA?}

One of the main reasons suggested by economic analysis on the need to carefully assess the full impact of institutions is the existence of the "principal-agent dilemma." This concept examines the issue of an "agent" as the obedient servant of its "principal" (Shapiro; Stiglitz). In this paper, the principal is the government and the agent is the subsidizing institution. This dilemma occurs when the compatibility between the motivations of the agent and those of the principal is not always guaranteed. The film policy is a good candidate for which to analyze this situation. On one hand, it is not a policy of prime importance for a government which has low incentives to closely monitor its agent operating in this sector. On the other hand, for reasons shown below, institutions in charge of the film subsidy policy can have strong connections with the private vested interests of the film industry (film companies, producers, actors, or movie theaters) that exert hard pressure on their loyalty to the principal. 
This loyalty is under even greater stress when, as will be illustrated in the next section, the decisions about the types of subsidies to grant, the timing of their introduction, and even their magnitude have been largely devolved to the institutions, granting them a substantial degree of freedom of action. It goes beyond this paper to analyze the reasons that have induced governments to grant such a degree of freedom. It could be the noble desire to create some healthy distance between politics and culture. Or it could be the fear of political power that those with key vested interests in the film industry hold; for example, famous directors or actors who through their media connections can influence the career/reputation of policy-makers.

There are thus good theoretical and empirical reasons to examine the institutions that operate film subsidy policies. However, until recently, scant attention has been devoted to them. The handful of existing studies are limited to a description of the number and features of the different instruments at the disposal of the institutions (Rouet; Lange and Westcott; Newman-Baudais; Milla, Fontaine, and Kanzler). Furthermore, they have not sought to connect them to the success of the film industries at stake through the use of rigorous economic analysis. It is fair to say that the reason for these limitations may be that these studies cover only European countries (with the exception of Québec for Rouet) - that is, a range of cases that are so similar in many respects that it is hard to draw any noteworthy lessons when comparing them.

In sharp contrast, the development of the Korean and French film industries offers a greater contrast that helps to draw meaningful lessons (Parc; Messerlin and Parc). In the mid-199os, Korea was lagging far behind France in each of the four main criteria of comparison: the size of the film market (the Korean film market was one-third of the French market in terms of admissions and box-office revenues), the annual number of admissions per inhabitant (1.1 in Korea and 2.5 in France), the share of the movie-goers watching domestic movies (20-25 percent in Korea and 35-37 percent in France), and the number of films produced (65 in Korea and 140 in France). Yet only twenty years later in 2016, the situation has completely reversed: a slightly larger film market in Korea than in France (admissions and box office), 4.2 admissions per inhabitant in Korea compared to 3.2 for France, 54 percent of movie-goers watching domestic films in Korea compared to 37 percent in France, and substantially more films produced in Korea than in France. ${ }^{2}$ Last but not least, this remarkable change has occurred with far smaller subsidies distributed in Korea than in France. In their peak year, 2014, the Korean subsidies amounted to barely one fourth of the French subsidies, whereas the revenues of Korean films at the domestic box office were 1.5 larger than the revenues of French films in their market (Parc and Messerlin). ${ }^{3}$ 


\section{THE FRENCH AND KOREAN INSTITUTIONS: VAST DIFFERENCES}

Table 1 provides the most important information on CNC and KOFIC (it does not, however, cover French and Korean regional institutions because they are small in both countries). CNC is clearly the dominant institution in France-a recent report from the French Senate does not hesitate to use the term "omnipotence" (Laborde). Subsidies from the French Ministry of Culture itself are small, and their use is usually handled by $\mathrm{CNC}$ in any case. In contrast, the Korean Ministry of Culture is more directly involved, with its own subsidy budget for the film industry amounting to US\$ 22 million in 2016.

Table 1. The institutions: budget, funding sources, coverage, 2016

\begin{tabular}{lcc} 
& CNC & KOFIC \\
\hline Date of establishment & $(1936) 1946$ & 1999 (2007) [a] \\
General mandate & Yes & Some influence \\
Prepare domestic regulations & Yes & Yes \\
Implement domestic regulations & Yes & No \\
Improve industry structure & Yes (since 1991) & No \\
International relations & $1948 / 10,72 \% / 168$ & $2007 / 3 \% / 45$ \\
Funding sources [b] & $1986 / 5.5 \% / 564$ & No \\
Tax on seat in movie-theaters & 1993 etc. / many / 20 & No \\
Tax on TV services & Small & Small \\
Tax on videos \& VoD [c] & Film, TV, video, games & Film, video \\
State budget [d] & & \\
Sectors covered & 868 & 62 \\
Resources: Budget and staff & 495 & 62 \\
Annual budget for all sectors & 41 & 9 \\
Annual budget for film only [e] & 471 & 130 \\
Operating budget & &
\end{tabular}


Number of films supported

Integrally domestic

Majority domestic

Minority domestic
209

81

74 [f]

$[\mathrm{g}]$

$[\mathrm{g}]$

Notes: [a]: 2007 is the year of the establishment of the Film Development Fund, KOFIC's financial arm. [b] respectively: year of introduction, current tax rate in \%, amount of current revenues in 2016 (in US\$ million). [c] this tax has been extended over the years to similar services, including most recently to internet operators. [d] does not take into account losses of tax revenues due to tax relief schemes. [e]: for France, includes support to horizontal actions (dispostifs transversaux) of interest for the film sector. [f]: KOFIC supports only independent films with a budget lower than US\$900,000. [g]: irrelevant.

Sources: France: CNC ("Bilan annuel" 251). Korea: Ministry of Culture, Sport and Tourism, Annual Budget Expenditure Planning (2016).

\subsection{Differences in existence, mandate, and supervision}

The first difference is the huge gap in terms of the length of their existence: more than seven decades for CNC compared to just two decades for KOFIC. ${ }^{4}$ This aspect may seem anecdotal at first, but in the context of the principal-agent dilemma, it is key for public institutions with some degree of freedom to act on their own. On the one hand, a long duration in existence could be seen as a positive source of knowledge and experience if information is shared among participants-that is, if there is no risk of the principal-agent dilemma. For example, CNC produces a remarkable set of data on the French film industry, with consistent time-series dating back from the 1970 s that are very useful for independent research. KOFIC, meanwhile, produces a similar set of data, the only limit being that some data from before 2004-2008 are less detailed (for instance, the various origins of foreign films released in Korea).

On the other hand, time has a negative impact if the information is asymmetrical (not the same for the principal and the agent). It then allows a long-lasting institution to reinforce its power vis-à-vis short-term political decision-makers who are largely unaware of the intricacies of film policies and increasingly complex subsidy schemes. In this case, time amplifies the principal-agent dilemma. This aspect has been magnified by the conditions that have existed in the creation of the institutions. KOFIC was reorganized at a time (1999-2007) when the general belief in the positive role of competition was strong in Korea. It was thus conceived as a positive way to embrace markets in an increasingly globalized world. In contrast, $\mathrm{CNC}$ is the heir of a private body (Confédération Générale du Cinéma) that was 
founded by private-vested interests within the film industry during the mid1930s. The dominant idea at this time was the notion of "organizing" markets by facilitating collusion among market participants with no international perspective. This "corporatist" view was endorsed by the Vichy government during the Second World War and was also confirmed by the French government in 1946 when CNC was created (Farchy; Hayward; CNC, "6o ans du CNC").

A second difference concerns the mandate of these institutions and their supervision. The CNC mandate includes the very important tasks to prepare and implement the regulatory framework as well as to advise on international issues, in particular on negotiations of trade agreements. The supervision of CNC by the French Ministry of Culture and by the French National Assembly or the Senate can be qualified at best as "notional." The result is that there are not many French public institutions who can make an independent review of CNC's policies. One of the few is the French Auditing Court (Cour des Comptes) which indeed has recently devoted a fair amount of attention, such as criticizing CNC for "unorthodox" financial procedures (Cour des Comptes, "La gestion", "Les soutiens"). However, the Court does not conduct such a process on an annual basis, and its recommendations do not lead automatically to any actual reform of the institution. For that to happen, they would need to be translated into political measures and enforced by legal means that require decisions from the government and/or the National Assembly. As yet, very few members of these institutions are ready to fight the powerful French film lobby. In contrast, the Korean Ministry of Culture keeps a tight grip on the Korean regulatory framework, and its relationship with KOFIC is supervised by the government. Within this framework, KOFIC has achieved some influence in terms of policy-making and implementation, but tensions between the Ministry and KOFIC can emerge on overlapping issues, which raises efficiency problems.

\subsection{Differences in funding sources and coverage}

Another important difference between CNC and KOFIC is the source of their funds, and their evolution over time. CNC funds have been based on an everexpanding array of sources: special taxes on theater seats (1948), TV operators (1986), videos and Video on Demand (1993, 2003, extended to all internet operators in 2007 and 2017). In contrast, KOFIC's Film Development Fund has been funded mostly by the seat tax since 2007. It is no surprise then, that $\mathrm{CNC}$ is the richer organization. Table 1 shows that the overall budget for $\mathrm{CNC}$ is fourteen times larger than KOFIC-largely because of the taxes imposed on TV operators which provides 65 percent of its total budget ("Les soutiens"). This setup has also allowed CNC to 
recruit and employ a large and stable staff - three times larger than KOFIC-which has been a key source for its influence in political circles and public opinion at large.

This wider base of resources has made it possible for $\mathrm{CNC}$ to follow a true "industrial policy" in the film industry. Table 1 shows that CNC is involved in almost every French film- "integrally French" (private funds are entirely French) or coproduced "majority French" (French private funds represent more than 50 percent of the private funds), or "minority French" (French private funds represent less than 50 percent of private funds). Indeed, until recently, French nationality was linked to being financed by $\mathrm{CNC}$ to the extent that a film was only considered a French production if it was subsidized by CNC. ${ }^{5}$ In sharp contrast, the more limited resources of KOFIC have prevented it from micromanaging the Korean film industry, inducing KOFIC to focus on independent art films with a small budget (less than US\$ 900,000 before marketing costs).

This larger base of resources has granted CNC a much wider mandate than KOFIC in terms of sectors covered. Not only is it in charge of the film industry, but it is also deeply involved in the production of films by the TV operators and of their screening by TV channels (though it shares this role with Conseil Supérieur de l'Audiovisuel). In contrast, KOFIC has no mandate in the TV sector. As a result, the economic fate of the French film and TV sectors has been linked by regulatory factors-a burden for both in the long run. In contrast, in Korea the film industry produces films and the TV sector produces TV dramas. If these two sectors have increasing relations, it is under the competitive pressures of digitization.

\section{3. "Fiscal autonomy": a blessing or a curse?}

The most important consequence of the seat tax (and of the other taxes listed in Table 1 in the CNC case) is that it has granted CNC and KOFIC "fiscal autonomy". In other words, these funds are not subjected to the basic principle of a public budget whereby a tax should not be raised in order to be allocated to a specific goal. Fiscal autonomy has been granted to $\mathrm{CNC}$ since its creation (simultaneously with the introduction of the seat tax) and it is very large since there are few funds transferred from the Ministry to CNC. In contrast, as mentioned above, KOFIC was only granted fiscal autonomy in 2007 , with the funds provided by the Ministry to KOFIC decreasing in turn. This change was presented as compensation for the cut in the Korean screen quota in 2006 (Parc). What follows explores the most remarkable features of the seat tax in order to assess its impact better. 
From a legal point of view, the seat tax is specific to the film industry: as stressed above, it is raised via the movie theaters, and its amount is exclusively allocated to the film industry. Hence, its revenues do not run the risk of being diverted to other sectors of the domestic economy (were the National Assembly to do so). This legal feature has enabled the vested interests in the film industry to tighten their grip on this instrument-firstly by making it permanent. The French seat tax created in 1948 was initially supposed to last only three years. Afterwards, this deadline was extended to five years, and later the seat tax was renewed in 1953 for four years before being definitively entrenched in the French legal system in 1959 (CNC, "6o ans du CNC"; Vezyrouglou and Péton). One further crucial step toward fiscal autonomy was achieved in 2007 when the movie theater operators were allowed to collect the seat tax rather than the French fiscal authorities (Cour des Comptes, "Les soutiens" 26). A similar evolution, though more limited, was observed in Korea, with the seat tax imposed in 2007 for five years, and then extended in December 2014 until December 2021.

From a political and economic point of view, the most remarkable feature of the seat tax is its capacity to coalesce the different vested interests of the film industry. This feature is crucial because these interests are antagonistic by nature. For instance, protecting a film industry by an import or a screen quota-the protectionist barriers used before subsidies-has the notable drawback that only one segment of the "chain of production" in the film industry is protected to the detriment of the others: import quotas benefit domestic importers, while screen quotas help domestic distributors. Ironically, none of these quotas benefit domestic filmmakers (Parc). In contrast, subsidies are able to smooth over conflicts among the various interests (segments) of the industry through a two-step process: first, all the vested interests unite in order to receive collectively the largest funds or support possible from the state; next, they negotiate among themselves on how to share these subsidies, often with the go-between help of the domestic subsidizing institution.

However, if these legal and political features of the seat tax (and of the other funds raised by the institutions) have made life easier for the vested interests of the film industry, the end result can be negative for the film industry as a whole in the long run. As stressed in the first section, although the French film industry is more subsidized than its Korean equivalent, this has not prevented it from suffering more in terms of audience size, market share, and annual number of movies produced. This shows that at some point, fiscal autonomy generates higher costs than benefits. In other words, not only did the lower rate of the Korean seat tax deter KOFIC from following the same industrial policy as $\mathrm{CNC}$, but it has also forced it to look for a better policy, rather than relying upon ever increasing subsidies. This point is revisited in the following sections. 


\section{COMPARING THE TYPES OF SUBSIDIES}

The debate on film subsidies has rarely be accompanied by a thorough discussion of the different types utilized and the respective pros and cons of their application. When facing a request from a vested interest, the institutions have generally reacted by designing a new ad hoc subsidy without examining its consequences on the other subsidies, nor on the film industry in the long run. This impulsive behavior has created an inflation of different types of subsidies. In 2011, there were no less than sixty types of French selective subsidies accounting for roughly US\$ 250 million (Cour des Comptes, "La gestion" 46). Over the last decade, KOFIC's budget has no less than one hundred different budgetary lines, most of them having small or intermittent amounts. This context makes for an interesting case to explore whether the abovementioned differences between France and Korea have ended up with alternative structures for their subsidy schemes, and if so, the consequences on the success of their policies.

\subsection{A broad typology of film subsidies}

As mentioned in the introduction, Parc was one of the first scholars to take into account an essential structural aspect by stressing the key difference between "direct" and "indirect" subsidies in the film industry. This distinction is crucial for designing an economically sound instrument for the public support of films. Indirect subsidies are designed to meet the basic infrastructure demands of the whole film business of the country, which makes their potential benefits large and widespread. For instance, public support for building the appropriate range of studios or skills (human capital) provides good working conditions and a qualified workforce at an affordable price for all the domestic filmmakers. If the market for renting studios or hiring from the labor market is not distorted by uncompetitive practices, studio and labor services will be used by the filmmakers offering the highest expectations in terms of success-as far as it is possible to predict success in this business.

One could argue that indirect public subsidies are not necessary, that private operators could invest in the film infrastructure. This has been the case with the famous Hollywood "bricks and mortar" studios in the 1920 s to the 1950 (and to some extent in China today, with the caveat that Chinese investors are often state-owned companies). This has also been the case for schools, actors, or special effects technicians. However, private operators may not provide the infrastructure for the socially desirable amount. As a result, indirect public subsidies can still be 
useful. They are somewhat akin to public investment in roads, railways, or internet infrastructure.

That said, there is always the risk that indirect public subsidies may end up supporting infrastructure that is too large or inadequate. The latter is likely to always be wasteful, but an oversized infrastructure is a more manageable issue. Such a situation can happen because of a fall or a decline in the domestic film industry: in this respect, the solution is to hire out studios to foreign filmmakers. An oversized infrastructure can also happen because governments want to attract foreign filmmakers at any cost. The decision by many countries to invest in their film infrastructure at the same time could then lead to a global excess supply of studios. This may have been the case during the last decade, with many governments investing in new studios or refurbishing old ones in order to attract foreign filmmakers (as was the case in Central or Eastern Europe). However, these examples should not dampen the principle of indirect public subsidies; rather they simply stress the need to follow a wise policy in this case.

In sharp contrast, the fact that each direct subsidy supports the production of a specific movie makes it intrinsically very risky-with a non-negligible probability to have net costs. Unfortunately, to our knowledge, systematic evidence on these net costs is not available. ${ }^{6}$ Direct subsidies are similar to the industrial policy of "picking the winners," with the subsidizing institution "betting" on the capacity of the filmmaker in question to produce a film profitable from a financial perspective or rewarding from a cultural point of view-depending on the criteria used by the institution. Advocates of direct subsidies argue that these schemes have at least the merit of generating a few successes. However, this argument does not take into account the opportunity costs when direct subsidies are granted. Since the total budget of the subsidizing institution is limited by the level of taxes raisedeven for a rich institution such as CNC. Granting a subsidy of US\$ 1 million to filmmaker "A" implies that filmmaker " $\mathrm{B}$ " or " $C$ " will not receive the same support, despite the fact that their movies could have been more profitable in financial terms or more rewarding in cultural terms. In other words, considering the high level of uncertainty in the film business, direct subsidies are doomed to have high opportunity costs - that is, to leave unfunded a significant number of film projects that could have potentially earned more financial revenue or generated more cultural value than the ones that were funded.

Institutions are well aware of these risks. They tend to address them by having recourse to technical advice from a large number of "experts" organized in committees. For instance, in 2011, CNC had 46 committees made up of 656 professional experts (Cour des Comptes, "La gestion" 50). The large number of committees does not eliminate (not even necessarily reduce) the intrinsic weakness 
of such an approach. It favors massively the incumbents in the long run-leading to a fall in cultural creativity and diversity. The vast majority of the "professional experts" is by definition working in the film industry-hence, it is composed of friends and/or competitors of the film producers who are supposed to assess the projects. This is all the more the case when the committee approach has lasted for decades. As a result, this approach in the long run generates an environment that is increasingly isolated from the demands of the movie-goers. Indeed, these flaws are serious enough to have been underlined by an official report which recommended the need for profound reform (Cour des Comptes, "La gestion" 50).

\subsection{Striking differences between France and Korea}

Keeping in mind this broad picture, it is now possible to make useful observations on the French and Korean subsidy schemes. Table 2 presents the subsidies granted in 2016 by CNC and KOFIC (leaving aside those distributed by the Korean Ministry of Culture in the context of its General and Special Accounts). Table 2 relies on the proposition that subsidies granted to the production, distribution, and movie theater segments are mostly "direct." This is because most of the subsidies in the production segment are granted to individual film projects, while most of the subsidies related to distribution are provided to specific large firms (Lalevé and Levy-Hartman), and most of the subsidies in the movie-theater segment are for large groups or individual movie theaters. In contrast, most of the subsidies granted for the promotion of the national film industry or for building physical and human capital can be classified as "indirect" subsidies since they do not target individual projects.

Table 2. The different types of subsidies, 2016

\begin{tabular}{lccccc}
$\begin{array}{l}\text { Segments } \\
\text { of the }\end{array}$ & \multicolumn{3}{c}{ All subsidies } & Automatic & \multicolumn{2}{c}{ All subsidies } \\
film industry & Mio $\$$ & $\%$ & subsid. [a] & Mio \$ & $\%$ \\
\hline $\begin{array}{l}\text { Direct subsidies } \\
\text { Production }\end{array}$ & 139.2 & 28.1 & 64.1 & 10.2 & 16.4 \\
$\begin{array}{l}\text { Distribution } \\
\text { Movie theaters }\end{array}$ & 54.8 & 11.1 & 78.4 & 0.4 & 0.7 \\
\hline Total & 167.5 & 33.8 & 49.3 & 2.9 & 4.6 \\
\hline
\end{tabular}




\begin{tabular}{lccccc}
\hline $\begin{array}{l}\text { Indirect subsidies } \\
\text { Infrastructure [b] }\end{array}$ & 69.2 & 14.0 & NA & 40.2 & 64.5 \\
Promotion & 64.2 & 13.0 & NA & 8.7 & 13.8 \\
\hline Total & 133.4 & 27.0 & NA & 48.9 & 78.3 \\
\hline Total & $\mathbf{4 9 4 . 8}$ & $\mathbf{1 0 0 . 0}$ & $\mathbf{4 3 . 4}$ & $\mathbf{6 2 . 4}$ & $\mathbf{1 0 0 . 0}$ \\
\hline
\end{tabular}

Note: Table 2 does not take into account public expenses generated by tax relief schemes. [a] Share of the automatic subsidies in all subsidies. [b] French indirect subsidies in infrastructure include support to horizontal actions ("dispostifs transversaux") important for the film industry. Korean support includes investment funds granted to various organizations (such as the Fund of the Funds).

Sources: France: CNC ("Bilan annuel” 251). Korea: Ministry of Culture, Sport and Tourism, Annual Budget Expenditure Planning.

Table 2 introduces an additional key distinction within the domain of direct subsidies by breaking them down into "automatic" and "selective" subsidies (these are terms used by $\mathrm{CNC}$ ). Automatic subsidies consisting of "drawing rights" are those made available to film producers according to the success of their previous movies at the box-office. Such subsidies can be particularly harmful from an economic perspective-and even more from a cultural point of view-to the extent that they reflect past production. Thus, they risk fossilizing film production, both in terms of companies and ideas. In contrast, selective subsidies seek to recognize promising film projects on the basis of a predefined set of criteria (renewal of talents, original scripts, etc.) to be used by the professional experts when making their judgment on the projects. To this extent, they are less harmful than automatic subsidies. Although, as mentioned above, they have a very high risk of having to pick winners in an unpredictable industry.

That said, Table 2 shows a striking contrast between CNC and KOFIC, going well beyond the differences shown in Table 1. The first main result from Table 2 is that it provides robust evidence supporting Parc's statement on direct vs. indirect subsidies. Korean support consists largely of indirect subsidies: 78.3 percent in the case of KOFIC, compared to a paltry 27 percent for CNC. Subsidies for infrastructure represent 64.5 percent in the case of KOFIC, compared to only 14 percent for CNC. ${ }^{7}$ It is also noteworthy that the largest share of the French film subsidies in 2016 was granted to the movie theater segment which absorbed almost 34 percent of the total amount of subsidies granted to the film industry-an awkward feature of the French subsidy policy which will be examined in more detail in section 4 . 
The second main result of Table 2 is the importance of the automatic subsidies among France's direct subsidies. In 2016, they represented 59.4 percent of the total public support to the production, distribution, and movie theater segments and 43.4 percent of the total amount of public support to the film industry.

All these results suggest that, even if it wanted to, KOFIC is less equipped than CNC to follow a micromanaged industrial policy: in particular, its limited funds constitute a strong obstacle to such an approach. This is all the more the case because automatic direct subsidies are a politically sustainable policy only if the overall amount of subsidies is large enough to satisfy most of the vested interests in the various segments of the film industry.

\section{CONSISTENCY OF THE SUBSIDY SCHEMES}

Rich institutions with a considerable degree of freedom, large fiscal autonomy, and a corporatist heritage are prone to grant, without much restraint, direct subsidies requested by their members. These features are not conducive to an economically sound approach which recognizes that any subsidy can have unexpected and unintended negative effects besides its expected positive impact for its narrow goal. They induce these institutions to ignore that the cost-benefit "balance" of any subsidy critically matters from the point of view of economic profitability as well as for cultural creativity; to oppose these two perspectives would be a mistake as will be below. Assessing this balance should be the core task of the institutions. However, it is rarely done because if they do not accept all the requests, they will face the ire of the segment of the film industry requesting the subsidy, and possibly endanger the fragile coalition of the antagonistic private-vested interests on which these institutions are based. This section presents two cases illustrating the costs of the inconsistencies among existing subsidies-one subsidy eroding or distorting the impact of other measures with ultimately a negative effect on cultural creativity.

\subsection{Seat tax and subsidies to movie theaters}

The first case examines the seat tax in conjunction with the subsidies granted to the movie theaters. Both Korea and France have adopted a seat tax, but there are two key differences. First, the Korean rate is much lower than the French rate-3 percent compared to 10.72 percent. Second, Korean subsidies to movie-theaters are only granted to art houses: that is, those specialized in exhibiting "Art et essai"

films. In contrast, French subsidies to the movie theaters are granted to all kinds of 
theaters. Table 2 shows that they are massive: for example, they amounted to US\$ 167 million in 2016, one-third of all the subsidies to the film sector. Moreover, they are granted under both forms (automatic and selective).

Such a large amount of subsidies raises a fundamental question. To what extent is it justifiable? After all, the movie theater segment is a very concentrated sector, dominated by large private firms. In France, ten movie theater chains account for almost 59 percent of all the admissions in 2017. Such large private firms should be more than capable enough to generate funds for their business, particularly as they screen entertainment films (as opposed to "Art et essai" films). Clearly, subsidies to "Art et essai" movie theaters make economic and cultural sense to the extent that these films have a positive impact on cultural creativity and diversity. Indeed, such subsidies were introduced in France in 1979 and in Korea in 2002.

In contrast, the French combination of a high seat tax and massive subsidies to the movie theaters screening entertainment films needs to be carefully examined. Interestingly, the level of French subsidies granted to the movie theaters (Table 2) matches almost perfectly the revenue of the seat tax (Table 1), a remarkable situation that has prevailed since 2011. In other words, the seat tax appears de facto as a revenue collected by the movie theaters to support them.

At first glance, such a tax-subsidy mix could be seen as a neutral operation. However, it creates many costs that need to be revealed. First, paradoxically it imposes costs on the movie theater sector itself in the form of lost audience. As the seat tax increases the ticket price paid by the movie-goers, it reduces the audience and revenues of the theaters compared to what the situation would have been in the absence of the seat tax (or in the case of a smaller tax). Interestingly, the number of movie-goers per inhabitant in France has grown by a meager 3 percent since 2000, despite the massive subsidies to movie theaters. And this number is lower than in Korea and the United States, two countries that have a flourishing film industry and do not subsidize their movie theaters.

Second, a smaller audience has two undesirable linked effects on French film production. First, it makes life particularly harder for French film producers: more expensive seats create a situation where movie-goers will have to limit their choices among the films regardless of their origin. Naturally, this creates fiercer competition among the films screened at movie theaters. Potential blockbusters or, more generally, films with a strong industrial support can cope with this increased competition. However, many French films are unlikely to meet these conditions, and hence are also unlikely to survive in this tougher environment, which demonstrates how the tax-subsidy mix discriminates against cultural diversity in the local film industry. This undesirable effect is amplified by a second one. Robust empirical 
evidence shows that French subsidies to the movie theaters discriminates in favor of US films to the detriment of French films (Messerlin and Parc). The reason is simple: by boosting the technical upgrading of the theaters, subsidies favor the screening of US films which are, on average, more hi-tech intensive than French films.

Who, therefore, gains from the current tax-subsidy system? The first group consists of the firms who equip the French movie theaters and benefit from both positive volume and price effect. Increasing subsidies to the French theaters expands, partly artificially, the demand for equipment (volume effect), and they also inflate the costs of this equipment (price effect). A second category of beneficiaries pertains to the movie theater segment itself, since some are likely to be more effective in gaining subsidies than others. In other words, the current taxsubsidy system favors some French theaters to the detriment of others on a basis that is not economically nor culturally sound. This risk is higher because half of the subsidies granted to the movie theaters are automatic which, as stressed in the previous section, favor incumbents.

Two options could be explored to improve the situation (both should be implemented progressively in order to allow for a smooth transition). First, the most drastic option would be to eliminate the seat tax and the subsidies to movie theaters altogether. Movie-goers will be better off: tickets will be less expensive, hence will generate larger crowds for watching films. Movie theaters as a whole will be better off due to a larger audience and also because they will adopt a more disciplined investment policy-the opposite effect of subsidies as a source of overspending. That said, it is likely that there will be winners and losers within the movie-theater segment. The rest of the French film industry-and particularly its film producers - will be in a healthier situation to the extent that there will be more potential movie-goers.

A "softer" option would be to eliminate only the automatic subsidies to the movie theaters (roughly US\$ 83 million) on the basis that they reinforce the position of incumbents for no economically or culturally sound reason. The positive impact of the tax cut will not be as great as in the first option because it is smaller. That said, the reduced seat tax could be used to fund selective subsidies to these movie theaters that would deserve such a treatment (art houses). Interestingly, in this second option, the reduced French seat tax rate (roughly 5 percent) would be close to the Korean rate (3 percent). As shown in section 1, the success of the Korean film industry provides ample evidence that such an option is unlikely to endanger the growth of the domestic film industry. 


\subsection{Tax relief for foreign filmmakers: boosting domestic demand for more subsidies}

The second illustration of potential reforms is related to the tax relief schemes that have become a key component among the film policies of major countries over the last decade (Parc and Messerlin). Tax relief is a complex instrument. They are de jure indirect subsidies to the extent that they are offered to all film producers under the same conditions and that they have a substantial infrastructure dimension. However, they are de facto direct subsidies because some filmmakers will be better at using them than others. The following part examines a recent change in the French subsidy policy, namely the adoption in 2014 of a new tax relief scheme targeting foreign filmmakers (the French acronym is "crédit d'impôt international." hereafter $\mathrm{C}_{2} \mathrm{I}$ ) in addition to tax relief which has been available to French filmmakers since 2004 (the French acronym is "crédit d'impôt cinéma," hereafter CIC). In contrast, in Korea, support for foreign filmmakers (for shooting or post-production in Korea) is limited, and it is not provided by KOFIC.

In a nutshell, $\mathrm{C}_{2} \mathrm{I}$ should reduce the benefits from the CIC subsidy scheme for French filmmakers, compared to the situation wherein $\mathrm{C}_{2} \mathrm{I}$ did not exist. Foreign film producers benefiting from $\mathrm{C}_{2} \mathrm{I}$ compete with French filmmakers to get access to these scarce resources in France, such as studios or attractive locations. These resources should then become more expansive for French filmmakers compared to how it was before the introduction of $\mathrm{C}_{2} \mathrm{I}$.

A more detailed analysis gives a sense of the main winners and losers. Introducing the $\mathrm{C}_{2} \mathrm{I}$ scheme generates foreign demand for French studios (assuming, for simplicity, that there was no foreign demand before) in addition to the French demand for studios. This higher overall demand increases the rental price of the French studios. French studios are thus winners, with a larger demand of their services and higher rental prices as well. Foreign filmmakers are also winners: the French $\mathrm{C}_{2} \mathrm{I}$ increases the world supply of studios they have access to. In contrast, the French filmmakers are losers: because of higher rental prices of the French studios, they have to reduce their demand for these studios or find affordable foreign studios (a search which is necessarily costly).

$\mathrm{C}_{2} \mathrm{I}$ can thus be analyzed as an implicit choice in terms of the industrial policy between two segments of the French film industry-French studios vs. French film producers. Ironically, the French film producers who are the closest competitors with the foreign filmmakers are likely to be the most hurt by $\mathrm{C}_{2} \mathrm{I}$ since they have a demand in terms of studios close to those of the foreign producers. 
The most frequent argument for justifying the introduction of $\mathrm{C}_{2} \mathrm{I}$ is the need to face competition by countries implementing massive tax relief schemes in favor of foreign film producers, such as the UK or Canada. This is not a very compelling argument. Why should CNC imitate the UK policy which has not solved the problems of the British independent film industry-and why should it not imitate the Korean policy which has contributed to enhance its domestic film industry?

\section{CONCLUDING REMARKS: SUBSIDIES AND REGULATIONS}

So far, the debate on film subsidies has mostly dealt with the overall amount provided. This paper shifts the focus to the "structure" of the subsidy schemes which depends on two essential factors: the institutions granting the subsidies and the detailed nature of these subsidies - whether they are direct or indirect, automatic or selective. Comparing the Korean and French institutions, this paper comes to the conclusion that a larger degree of freedom and fiscal autonomy combined with a larger budget has led to a less successful film policy. The most fundamental reason for this result is that rich institutions are prone to grant without a detailed assessment of the subsidies sought after by vested interests and that they tend to keep an economically unsound structure of subsidies (too high a proportion of direct automatic subsidies and too low a proportion of indirect subsidies). Lastly, this paper examines in depth two cases of subsidies that have been introduced without paying attention to the inconsistencies they create in the film industry. It suggests options for reforms which would make the French subsidy system closer to the Korean one which has accompanied the remarkable growth of the Korean film industry. More generally, this paper seeks to contribute to a pragmatic and substantive debate on how to support the film industry of a country in the most efficient way-again from an economic and cultural perspective.

This paper has focused on subsidies which are among the most important public policies in the film industry. However, other policies can interfere with the provision of subsidies. For instance, there are rigid legal obligations between the cinema and TV sectors in some countries. These obligations have often been the "price to pay" for receiving large subsidies. For instance, the mandatory funding of French films by TV channels has been "paid" by a rigid sequencing of the release of movies in theaters and TV channels ("chronology of the media"). Ultimately, these regulations have harmed the prosperity of both the film and broadcasting sectors. There is thus a need for more studies on the theme of "consistent policies" which would explore the interactions between subsidy policies and regulations imposed on the film industry or on its related sectors, such as broadcasting. 


\section{Acknowledgement}

This work was supported by the Laboratory Program for Korean Studies through the Ministry of Education of the Republic of Korea and the Korean Studies Promotion Service of the Academy of Korean Studies (AKS-2015-LAB-2250003). 


\section{Notes}

1. I would like to thank the two referees for their very useful comments, Dongjoon Doh (Film Policy Research Institute, KOFIC), Kyuchan Kim, Yeon Lee, and Jimmyn Parc for their invaluable help.

2. Excluding films under co-production since the Korean film industry rarely uses this format, reportedly 12 to 18 films per year in 2015-2016.

3. This paper concentrates on subsidies stricto sensu and excludes French and Korean tax relief schemes. For details, see Parc and Messerlin.

4. In fact, KOFIC was first established in April 1973. However, it underwent profound reform in 1999 (the year mentioned in Table 1). Its financial arm (the Film Development Fund) though was established only in 2007, following the introduction of the seat tax in 2006. As a result, for this paper that seeks to compare CNC and KOFIC, the most accurate birthdate for KOFIC seems to be 2007.

5. The most ironic illustration of this link is The tree, the mayor and the mediatheque ("L'arbre, le maire et la médiathèque ou les sept hasards"), a film profoundly "French" in its inspiration and style which was produced in 1993 by the renowned French director Eric Rohmer with no CNC support.

6. A couple of indicators suggest that these net costs are large. In France, the percentage of financially profitable films is low (10 to 15 percent) even after treating direct subsidies as a contribution to the costs (CNC 2013; Legras). Only 5 percent of direct subsidies (avances remboursables) granted as "advances" to be reimbursed when the films are released have been reimbursed during the period 2001-2010 (Cour des Comptes, "Les soutiens" 37).

7. It is noteworthy that, since 2015, KOFIC direct subsidies to producers have increased, while indirect subsidies to infrastructure have decreased. However, this drift is still limited: in 2017, all the indirect subsidies amount to 72 percent of the total support. This evolution happens in the context of a decline of total KOFIC support which is in 2017, two-third of its amount in 2012 (the peak year). 


\section{Works Cited}

CNC (Centre National du Cinéma et de l'Image Animée). "6o ans du CNC." Centre National du Cinéma et de l'Image Animée, 2006, http://www.cnc.fr/. Accessed 31 May 2018.

--. "Bilan annuel." Centre National du Cinéma et de l'Image Animée, 2016, http://www.cnc. fr/. Accessed 31 May 2018.

--. "L'économie des films français." Centre National du Cinéma et de l'Image Animée, 2013, http://www.cnc.fr/. Accessed 31 May 2018.

Cour des Comptes. "La gestion et le financement du Centre national du cinéma et de l'image animée. Exercices 2007 à 2011." Cour des Comptes, 2012.

-.. "Les soutiens à la production cinématographique et audiovisuelle: des changements nécessaires." Rapport thématique public. Cour des Comptes, 2014.

Hayward, Susan. French National Cinema. Routledge, 2005.

Farchy, Joëlle. Le cinéma déchaîné. Mutation d'une industrie. Presses du CNRS, 1992.

Kornai, Jason. "The Soft Budget Constraint." Kyklos, vol. 39, 1986, pp. 3-30.

Laborde, Françoise. Avis sur le projet de loi de finances 2018. Tome IV, Fascicule 3, Médias, livre et industries culturelles: livre et industries culturelles. Sénat, République Française. Session ordinaire de 2017-2018, No. 112. www.senat.fr/rap/a17-112-43/a17112-43o.html. Accessed 31 May 2018.

Lalevée, Fabrice, and Florence Lévy-Hartman. "Le soutien à la production cinématographique française : A qui profite l'exception culturelle française?" Groupe d'Economie Mondiale, Sciences Po, Working paper, Jan. 2007.

Lange, André, and Tim Westcott (with the collaboration of Olivier Debande and Susan Newman). "Public Funding for Films and Audiovisual Works in Europe. A Report by the European Audiovisual Observatory." European Investment Bank, 2004.

Legras, Sophie. "Cinéma francais: 90\% des films ne sont pas rentables." Le Figaro, January 2014, www.lefigaro.fr/cinema/2014/01/o8/03002-20140108ARTFIGo0429-90-desfilms-francais-ne-sont-pas-rentables.php. Accessed 18 May 2018.

Messerlin, Patrick, and Jimmyn Parc. "The Real Impact of Subsidies on the Film Industry (1970s-present): Lessons from France and Korea." Pacific Affairs, vol. 90, no. 1, 2017, pp. 51-75.

Milla, Julio, Gilles Fontaine, and Martin Kanzler. "Public Financing for Film and Televisions Content in Europe. A Report by the European Audiovisual Observatory." Council of Europe, 2016.

Ministry of Culture, Sports and Tourism. Annual Budget Expenditure Planning. 2016.

Newman-Baudais, Susan. "Public Funding for Films and Audiovisual Works in Europe. A Report by the European Audiovisual Observatory." Council of Europe, 2011.

Parc, Jimmyn. "The Effects of Protection in Cultural Industries: The Case of the Korean Film Policies." The International Journal of Cultural Policy, vol. 23 no. 5, 2017, pp. 618-633. 
Parc, Jimmyn, and Patrick Messerlin, "In Search of an Effective Trade Policy for the Film Industry: Lessons from Korea." Journal of World Trade, vol. 52, no. 5, 2018, pp. 745-764. 2018.

Rouet, François. Des aides à la culture. Edition Mardaga, 1987.

Shapiro, Carl. "Premiums for high quality products as returns to reputations." Quarterly Journal of Economics, vol. 98, no. 4, 1983, pp. 659-80.

Stiglitz, Joseph. "Principal and Agent." The New Palgrave Dictionary of Economics, edited by John Eastwell, Murray Milgate, and Peter Newman, Stockton Press, 1987, pp. 241-251.

Vézyrouglou, Dimitri, and Gaël Péton. "La politique française du cinéma au moment du rattachement du Centre National de la Cinématographie au Ministère des Affaires Culturelles (1957-1962)." Le Cinéma: Une Affaire d'État (1945-1970), edited by Dimitri Vézyrouglou. La Documentation Française, 2014, pp. 27-57. 